\title{
Review of Music for Women (Survivors of Violence): A Feminist Music Therapy Interactive eBook (2019) By Sandra L. Curtis
}

\author{
Susan J Hadley ${ }^{1}$ * \\ 1 Slippery Rock University, USA \\ *susan.hadley@sru.edu
}

Received: 19 June 2021 Accepted: 21 September 2021 Published: 1 November 2021

Editor: Alexander Crooke Reviewer: Megan Steele

\begin{abstract}
This article is a review of Sandra L. Curtis' book, Music for Women (Survivors of Violence): A Feminist Music Therapy Interactive eBook (2019). Published by Barcelona Publishers, Dallas TX, USA. E-ISBN: 9781945411465
\end{abstract}

Keywords: feminist music therapy, male violence against women, songs

It was 24 years ago to the month (at the time of writing this book review) that I first met Dr. Sandra Curtis. I was filled with excitement, awe, and trepidation as I traveled to Georgia (USA) for an interview for a university teaching position. It was my very first academic interview and as fate would have it, the interview was with the only person I knew of at the time who was engaging in feminist music therapy. I felt added pressure to impress her given my own passion for feminism. While I did not accept the job offer due to my personal circumstances at the time, this was not my last interaction or opportunity to work with Sandi. Approximately 8 years later, Sandi was one of the first people I invited to contribute to my edited book Feminist Perspectives in Music Therapy, given her groundbreaking work in feminist music therapy. Then, approximately six years later, Sandi invited me to be one of the keynote speakers for the joint Canadian Music Therapy Association's $38^{\text {th }}$ Annual Conference and the Inaugural Gender, Health and Feminist Music Therapy Conference in Montreal, Canada, given my work as editor of the first book on feminist perspectives in music therapy. So, it feels fitting now to write this review of Sandi Curtis' new book, Music for Women (Survivors of Violence) which is the culmination of decades of her work engaging in feminist music therapy with women.

As Curtis indicates, Music for Women (Survivors of Violence) has three target audiences: women in general, as all women have been impacted by violence against women; professionals, in general, who work with women survivors of violence; and music therapists who work with women survivors of violence as well as music therapy educators. The book is aimed to be a resource for each target audience. While these are the expressed target audiences, I would say that this book is an important read for cis- 
gender, heterosexual men as a means for understanding how patriarchy and misogyny impact all of us, particularly the ways in which they perpetuate these oppressive systems. As Curtis states, we are all impacted by male violence against women, whether overt or covert, in some way or another. Furthermore, while Curtis does not state the gender of the professionals/music therapists who are target audiences, she does not directly address the role of male identifying therapists in dismantling the culture of male violence against women within a feminist music therapy approach, or the complexities involved in such work. However, this book will have many helpful resources for male identifying music therapists to use in conjunction with some deeply reflexive work that is also necessary.

Before commenting on the specific topics covered in the chapters, there are several features of this book that are worth mentioning from the start. One great feature of the book is its interactive structure. That is, throughout the book, Curtis provides links to songs from a wide variety of genres and other resources that are directly related to what she is discussing within the body of each chapter. In addition to these links, in the penultimate chapter, Curtis provides a resource of songs for women by women singer/ songwriters, first listed in alphabetical order by title, then by artist, then by theme, and lastly by genre. For each song, all relevant information pertaining to it is included. This feature in and of itself is a wonderful resource. Another invaluable resource for music therapists is in the eighth chapter, in which Curtis provides a detailed outline of an 8-week music therapy program for use with women survivors of violence. This resource includes session plans with related resources and reading materials for eight 2-hour sessions. There are four different plans for the third session depending on which group a music therapist is working with: women in general, women survivors of intimate male partner abuse, women survivors of male sexual assault, or women survivors of childhood sexual abuse. This music therapy program is informed by Curtis' decades of work with women survivors and as such is a rich resource for music therapists.

Not only does Curtis provide this important resource to music therapists, but in the chapter prior to this one, she provides valuable resources to the other two target audiences of the book. After outlining what music therapy is and what feminist music therapy is, Curtis discusses the different needs that can be met talking to friends versus working with a therapist. She also discusses the difference between engaging with music alone and with a trained music therapist. She then provides guidelines for women and women survivors of violence for engaging with music as a resource for oneself and when and why one should seek music therapy, as well as information about how to find a music therapist with whom to work. In addition, she provides guidelines for professionals working with women survivors of violence in terms of how they can use music within their work, as well as when to call a professional music therapist and how to find a trained music therapist. This modeling of how to communicate ways of engaging with music as a health resource with or without a music therapist is great to have, especially for music therapists who have a belief that only music therapists can provide music for therapeutic gains.

The first section of the book, chapters 1 through 6, provides wide-ranging information about the ways in which women's health and well-being is impacted by their gendered oppression. In chapter 1 , Curtis provides readers with information about the meaning of gender (largely in terms of the cisgender binary while acknowledging its fluidity). In chapter 2 , she discusses issues related to self-esteem, confidence, resistance, and resilience, and the impact of these on well-being. Chapter 3 focuses on different forms of power that go beyond the domination of "power over," such as "power with," "power to," and "power within." While most people associate the concept of power with having power over others, there are many positive aspects of power. Curtis also discusses barriers facing women in terms of accessing power. Additionally, she describes empowerment as a complex, multidimensional process, one that can be both personal and systemic. Other distinctions that she draws are between public (employment, economics, politics), private (relationships with family, friends, 
intimate partners), and intimate (relationship with self, self-esteem, confidence, physical and mental health) forms of empowerment.

Women, power, and love are discussed in chapter 4. While this chapter, and indeed the entire book, focuses on heteronormative relationships and cisnormative assumptions of gender, Curtis repeatedly acknowledges that there is no universal woman, and no universal experience of woman-ness. And within this chapter, she discusses various intimate partner relationships, sometimes comparing differences and similarities between heterosexual relationships and same-sex relationship dyads. For each, she discusses that when there is greater equality of power, there is greater relationship stability, satisfaction, intimacy, communication, etc. However, when there is inequity of power, there are emotional and physical health costs for the person with less power, and relationship stability and intimacy are negatively impacted. These impacts are compounded if there is violence within the relationship.

In chapter 5 , Curtis discusses issues of diversity in terms of race, gender, sexuality, and disability. She discusses intersectionality and how, based on the combination of our sociocultural identities, we are differentially located along sociocultural lines. In this chapter Curtis discusses commonalities of experience for women as well as differences. Quoting Audre Lorde, Curtis notes that it is "not our differences that divide us. It is our inability to recognize, accept, and celebrate those differences" (Chapter 5, para. 14). In this chapter, Curtis also discusses important "don'ts" and "dos" of allyship.

Chapter 6 is the final chapter of part one of the book and is filled with a great deal of information about overt and covert forms of male violence against women. Curtis provides statistics from the United States and Canada, the two countries in which she has lived and worked. She outlines the higher incidences for BIPOC, disabled, lesbian, and trans women. She acknowledges that lesbian women do experience intimate partner violence, but they experience greater incidences of violence from males. Incidence of sexual assault according to age is also explored in this section. Curtis also discusses the under-reporting of sexual assault and reasons for that. She explains that sexual assault is more under-reported by BIPOC due to their experiences of being disbelieved, trivialized, and retraumatized when reporting. Also discussed is the fear of reporting intimate partner violence that many women experience because of threats to their personal safety; distrust of the legal system; and fear of retaliation, bringing shame, reaction of others, and being blamed. Curtis discusses the culture of male violence against women and how this impacts all women and girls, whether or not they experience it first-hand, because they know it could happen to them. She explores what it would take to dismantle the culture of male violence against women. Towards the end of this chapter, Curtis discusses how women's activism has reignited through social media platforms and how encouraging this renewed movement has been in terms of gender equity.

Music for Women (Survivors of Violence): A Feminist Music Therapy Interactive eBook achieves what it set out to do. The first part (chapters 1-6) provides a broad base of information about gender, its impact on women's health and well-being, women's selfworth, confidence, resistance and resilience, power/empowerment, love, issues of diversity and intersectionality, and data on male violence against women. The second part (chapters 7-10) provides guidelines for music therapists, other health professionals, and women survivors and others interested in personal growth, for how to engage in music for personal and collective health and well-being, and as a form of activism. Engaging in the interactive process at the core of this book is empowering for music therapists and other professionals working with women survivors of violence, and for women in general as we work to dismantle the culture of violence against women and to listen to the powerful music of women singer/song writers as we work towards personal and collective healing and wholeness. 


\section{About the author}

Susan Hadley, PhD, MT-BC, is professor of music therapy at Slippery Rock University, Pennsylvania. Her books include Sociocultural Identities in Music Therapy (2021), Experiencing Race as a Music Therapist (2013), Therapeutic Uses of Rap and Hip Hop (2012), and Feminist Perspectives in Music Therapy (2006).

\section{References}

Curtis, S.L. (2019). Music for women (Survivors of violence): A feminist music therapy interactive eBook. Barcelona Publishers. E-ISBN: 9781945411465 